\title{
Las pasiones políticas en la Grecia clásica. Introducción Political Passions in Classical Greece. Introduction
}

\author{
Diego S. GARROCHO SALCEDO \\ Universidad Autónoma de Madrid \\ garrocho.salcedo@gmail.com
}

DOI https://doi.org/10.20318/fons.2019.5468

En el año 1985 Peter N. Setearns y Carol Z. Stearns publicaron un artículo que llevaba por título «Emotionology: Clarifying the History of Emotions and Emotional standards» ${ }^{1}$. Como tantas veces en la ciencia, el feliz cuño de un nuevo término y el desarrollo de algunas hipótesis que hasta la fecha habrían resultado más o menos insólitas, sirvió para operar lo que en muchos círculos académicos ha venido a reconocerse, retomando una vieja estrategia nominativa, como el Affective Turn o el Emotional Turn. Aquella fecha, discutible como cualquier hito discreto que quiera pautar el verdadero origen de algo, marcó el nuevo protagonismo que a partir de entonces adquiriría el tratamiento académico de las emociones, las pasiones o la afectividad en general, una preocupación que para algunos estudiosos no habría encontrado precedentes quizá desde la Grecia antigua.

Algunos historiadores como Rob Boddice (2018) no dudan en reconocer en Tucídides un sólido precedente en lo que ha podido distinguirse como la historia de las emociones, una disciplina que goza de un creciente arraigo en las escuelas y facultades de artes y humanidades de todo el mundo (ejemplos de ello son el Centre for the History of Emotions, de la Queen Mary University of London, o el Center for the History of Emotions del Max-Planck Institute for Human Development). Para cualquier historiador riguroso -en virtud del significado específico que tenía el término griego íotopía- la labor desempeñada por Tucídides no podría, sin embargo, asimilarse a la tarea que a partir del siglo XIX se reconoce bajo el rubro académico de historiografía. Del mismo modo, cualquier consideración analítica sobre la historia de los conceptos nos exigiría demarcar con mucho más rigor las fronteras semánticas y conceptuales existentes entre términos afines como lo son los afectos, las pasiones, las emociones y los sentimientos.

Si buscamos precedentes griegos y latinos de cada uno de estos vocablos y su arraigo en la experiencia histórica la empresa se haría poco menos que imposible. Sin

\footnotetext{
${ }^{1}$ Stearns-Stearns 1985.
}

ПНГН/ F O N 4 (2019), 9-13

ISSN 2445-2297 www.uc3m.es/pege
D. S. GARROCHO SALCEDO, Introducción DOI https://doi.org/10.20318/fons.2019.5468 
embargo, autores tan autorizados como Amelie Rorty (1982), o más recientemente Thomas Dixon (2003), han emprendido un esfuerzo definicional que justificadamente nos permite concluir que, en efecto, hay un universo experiencial común entre lo que un psicólogo contemporáneo denomina "emoción" y aquello que un griego del siglo IV pudo denominar con el término mó́tos. Sabemos que el tratamiento de las pasiones varió enormemente en el tránsito de un contexto cultural a otro e incluso podríamos precisar los matices inherentes al tratamiento de las pasiones en la obra de un mismo autor. Así, por ejemplo, la descripción que Aristóteles realiza de las pasiones en Retórica dista mucho de ser enteramente coincidente con la aproximación que realizara en sus éticas. A pesar de ello, y como advierte David Konstan (2006), hoy somos capaces de reírnos con las comedias de Aristófanes y albergamos la esperanza de poder inteligir el primer verso de la Ilíada. Aunque nunca sepamos exactamente qué pudo experimentar Aquiles cuando se nos habla de su cólera, secretamente sospechamos que somos capaces de entender a qué remite Homero cuando invoca esa pasión en el canto de la Diosa.

Obviando precedentes científicos tan relevantes como Charles Darwin o William James a finales del siglo XIX, el interés humanístico contemporáneo por las emociones se haría inexplicable sin la singularísima intervención que sobre su estudio histórico inauguró Lucian Febvre. Aunque fuera la década de los 80 la que terminaría de asentar el protagonismo de la vida emocional en la investigación académica, fue la posibilidad de historiar experiencias y vivencias absolutamente ordinarias como los celos o la envidia lo que permitió incardinar la experiencia emocional en un marco histórica y socialmente construido. A este respecto, la aportación de Febvre y la Escuela de los Anales resultó del todo decisiva. Si las emociones son susceptibles de ser analizas históricamente y si su vivencia y expresión está determinada social, cultural y políticamente, parece imprescindible remontarnos al origen de nuestra tradición cultural para intentar desentrañar el modo en que estas emociones nos constituyen. Nuestra gramática afectiva y el modo en que políticamente pudieron troquelarse las pasiones en la Grecia antigua serán acontecimientos determinantes para poder reconocer hasta qué punto somos -o no- deudores de aquel modo de vivir y de nombrar y la recuperación de la fuente griega se tornará en un ejercicio imprescindible de autoconocimiento.

Es curioso cómo la síncopa de los estudios históricos en relación con las pasiones resulta casi coincidente. Uno de los textos más determinantes para la historia de las emociones, con hallazgos casi fundacionales, fue el libro de la medievalista Barbara H. Rosenwein Emotional Communities in the Early Middle Ages, un volumen al que la hipótesis de este monográfico tanto debe. Aquel texto, incardinado en una tradición donde la influencia de Huizinga seguía haciéndose evidente, se editó en el mismo año, 2006, en el que David Konstan publicara The Emotions of the Ancient Greek, probablemente el gran precedente en los estudios clásicos sobre emociones. En el 
origen de gran parte de estos estudios y confesando nuestra vocación más política debemos reconocer otra influencia incuestionable como es la de William Reddy, quien acuñó un término que terminaría por apuntalar un nuevo marco de interpretación de la realidad social y cultural y, con ello, de toda experiencia emocional. El concepto de "régimen emocional", vertebral en la concepción del libro The Navigation of Feeling. del año 2001, vino a describir la inserción de las emociones en un marco esencialmente político y normativo en el que la ritualización y expresión de las pasiones aparecía fuertemente pautada. La hipótesis, no exenta de críticas, no vino sino a poner en claro algunas intuiciones que podrían hacerse reconocibles en textos muy anteriores e incluso no pocos serían capaces de reconocer en autores como el propio Nietzsche un precedente significativo.

En cualquier caso, lo que sí parece que está fuera de toda duda, es que una reconstrucción histórica de las pasiones requiere un análisis esencialmente político y que dicha normativización o régimen de expectativa justificaba la pertinencia de un estudio monográfico en castellano de las pasiones políticas en el mundo clásico. Pocos contextos como la Grecia antigua nos han legado textos tan centrales para la construcción cultural de la experiencia emocional. Desde la tragedia ática hasta la lírica, pasando por el tratamiento específico de algunos hitos centrales del pensamiento filosófico o las comedias, el modo en el que todavía hoy somos capaces de emocionarnos y de narrar nuestras pasiones debe mucho, empezando por la propia palabra pasión, a aquel contexto cultural.

El presente número de Pegé no busca sino disponer un conjunto de estudios plurales en torno a la condición política de las pasiones humanas en la Grecia antigua. Los temas abordados e incluso las disciplinas y metodologías convocadas son lo suficientemente libres como para intentar ofrecer una panorámica global y no necesariamente limitada por las adscripciones temáticas y las áreas de conocimiento que hoy ordenan los estudios. Así, en algún sentido, el presente número aspira a compendiar las inquietudes de un conjunto de humanistas o, si se prefiere en una terminología aún más intempestiva, de gentes de letras: investigadores y docentes provenientes de tradiciones académicas puede que disjuntas pero llamadas a converger en preocupaciones que son, y de qué manera, perfectamente comunes. Para ello hemos intentado mantener el pulso coherente con la calidad mostrada por esta publicación en la que en números precedentes han participado investigadores de un incuestionable reconocimiento internacional. La entrega que ahora presentamos no es una excepción y como editor de este monográfico debo expresar mi singular gratitud con todas y cada una de las personas que quisieron reunir sus reflexiones para intentar volver a pensar juntos en qué modo los griegos determinaron nuestra experiencia emocional en clave esencialmente política. 
En las siguientes páginas se dan cita autoridades académicas de sólidas credenciales a las que, quien escribe estas páginas, debe no poco de lo que se ha atrevido a expresar en otros contextos. Por este motivo debo certificar una deuda íntima y a la vez pública con los profesores y profesoras que nutren este número: Nuria Sánchez Madrid, Emiliano Buis, Álvaro Vallejo Campos, Gustavo Gómez, Begoña Ramón, Iván de los Ríos, Henar Lanza, Inmaculada Hoyos y José Luis Velázquez. Gracias a todos ellos este número servirá para arrojar algo de luz proveniente de un lado y otro del Atlántico sobre el modo en que la emotividad política griega nos sigue interpelando. Debo hacer también extensiva mi deuda con los responsables de esta prestigiosa publicación. Gracias, pues, al profesor Francisco Lisi y al profesor Michele Curnis, quienes demostraron una generosidad rayana en la temeridad cuando me confiaron la edición de este número. Espero que las muchas virtudes de quienes escriben en este monográfico alcancen a maquillar mis propias limitaciones y que, con suerte y con esa ayuda, haya sido capaz de responder a su confianza. Y gracias, por supuesto, al Instituto de Estudios Clásicos para la Sociedad y la Política "Lucio Anneo Séneca" de la Universidad Carlos III, por auspiciar una publicación como Pegé-Fons y por haberse convertido en un referente ineludible en el panorama académico del mundo clásico.

Existen en las páginas que siguen ideas controvertidas, arriesgadas, tentativas y fundadas. Descripciones en ocasiones en conflicto -afortunadamente- y tratamientos metodológicamente divergentes a través de los cuales la siempre fascinante cultura griega nos resulta accesible. No sólo a la naturaleza, como dijera Heráclito, le gusta esconderse, sino que también los implícitos políticos y morales que determinan nuestra conducta suelen escamotearse de la superficie más visible de nuestra identidad cultural y moral. Gran parte de los problemas que nos asedian tienen algún precedente remoto en la Grecia antigua y las páginas que siguen nos ayudarán a cuestionar algunos de nuestros más arraigados prejuicios y algunas de nuestras más perezosas certezas. Lo dijo una vez Aristóteles mencionando a Hesíodo y quizá aquellas palabras habrían de servir para justificar nuestra preocupación por las emociones políticas. El principio, dijo el de Estagira, es más de la mitad del todo, y no cabe duda de que el principio de nuestra sensibilidad y de nuestras pasiones se encuentra irremediablemente marcado a fuego por la experiencia griega (ENI 1098b 7). Confío, y estoy seguro de ello, en que la luz que arrojan las investigaciones que siguen sabrán ser de utilidad para una prosperidad futura que ojalá, también en clave política, nos aguarde.

\section{Bibliografía}

Aristóteles (1985), Ética Nicomáquea - Ética Eudemia, trad. cast. por J. Pallí Bonet, Madrid. Boddice, R. (2018), The History of Emotions. Historical Approaches, Manchester. Dixon, Th. (2003), From Passions to Emotions: the Creation of a Secular Psychological Category, Cambridge-New York. 
Febvre, L. (1941), «La sensibilité et l'histoire: comment reconstituer la vie affective d'autrefois?», Annales d'histoire Sociale (1939-1941), III 1-2, 5-20.

Konstan, D. (2006), The Emotions of the Ancient Greeks: Studies in Aristotle and Classical Literature, Toronto.

Reddy, W.M. (2007), The Navigation of Feeling, Cambridge.

Rosenwein, B.H. (2006), Emotional Communities in the Early Middle Ages, Ithaca, N.Y.

Rorty, A. Oksenberg (1982), «From Passions to Emotions and Sentiments», Philosophy 57 (220), 159-172.

Stearns, P.N. - Stearns, C.Z. (1985), «Emotionology: Clarifying the History of Emotions and Emotional Standards», The American Historical Review 90 (4), 813-836, doi: 10.2307/ 1858841. 